\title{
Driving license detection using QR code
}

\author{
Bhavani Ratakonda ${ }^{1 *}$, Ajay Therala $^{2}$, and Chanikya Kumar Hanumanthu ${ }^{3}$ \\ ${ }^{1}$ Assistant Professor, Department of IT, Gokaraju Rangaraju Institute of Engineering \& Technology, Hyderabad, India. \\ 2 B-Tech Student, Department of IT, Gokaraju Rangaraju Institute of Engineering \& Technology, Hyderabad, India. \\ ${ }^{3}$ B-Tech Student, Department of IT, Gokaraju Rangaraju Institute of Engineering \& Technology, Hyderabad, India.
}

\begin{abstract}
We have proposed a system in which it simplifies the work of traffic police in detecting the fake driving license users. RTO Employee can login into this system and generate a new driving license with QR code for every applicant who has undergone test drive and who has successfully secured their learning license. In this system every employee can login with their credentials, they can generate a QR code and they can enter the details of applicant and generate new license with QR code attached to it. Traffic police can scan this QR code through Scanner app from mobile phone to retrieve the data present in $\mathrm{QR}$ code, if data retrieved in scanner app and data on the license mismatches then police can conclude that user is a fake user. QR code on the driving license contains name, father's name, date of birth, house no., address and date up to when the card is valid.
\end{abstract}

\section{INTRODUCTION}

Regional Transport Office (R.T.O) is a Central government authority which has the major responsibility as issuing driving licenses. This project targets to store information related to license, personal details of the holder of the card. For every applicant new card will be issued with QR code attached with it. Now-a-days people below 18 years are editing their details and preparing fake driving license which is most offensive crime. Here comes the QR code provided on the license into play, the traffic police should have a scanner app to scan the QR code [3], immediately he will be able to see the details of user and if he finds any mismatch in details then the user is a fake user and he will be called for counseling along with their parents.

\section{LITERATURE SURVEY}

Komal chorhgade, Piyush Dahiwele, Prof. Prajakta pise (2018) [6] has developed RTO AUTOMATION USING QR CODE, in which there were different modules in which they store the information. In RTO it had process of registration of driving license, their documents data to be stored in the database in which they access from that database whenever required. This system also provides feature for detecting the fake user. Administrator had rights to enter and process the data of applicants. Any person who has been authorized by the administrator can utilize the services of his system. An authorized user should have a user name and a password.
Manjunath S.Patil, Basavaraj K. Madagouda, Vinodh C Desai (2013) has developed E-RTO MANAGEMENT SYSTEM. [7] The author developed a system which provides services driving licenses. Administrator is the power user, he has power to verify the data entered and also process the data and he can provide access for the authorized users to utilize the services of the system.

\subsection{EXISTING SYSTEM:}

License card with smart chip, to read this a special device called smart card reader is required. This kind of special device is available only near authorized traffic police.

\subsection{PROPOSED SYSTEM:}

License card with QR code which can be easily scanned through the scanner app and every traffic police who are using smart phones can easily detect by scanning QR code.

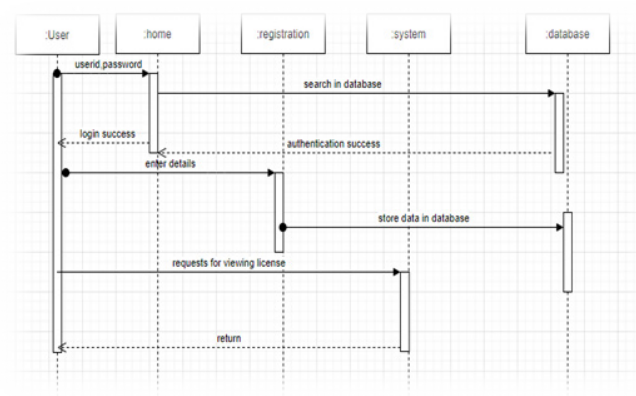

Fig. 1. Event scenario for the proposed framework. 


\section{Implementation of Frame Work}

The main intention of developing this system is to avoid the usage of magnetic card readers for detecting fake users. In our frame work authorized users can login by using credentials [4] provided by the administrator, after signing into the system user will produce QR code [1] and enter the data about each applicant such as name, father's name, date of birth, address, vehicle type and the region applicant belongs to. After successful enrollment information will be transferred into database [2], we can access the data from the database [3]. For the implementation of our system we have utilized the services provided by Flask frame work which provides basic HTTP tasks. Frame work is the collection of numerous modules that can be used for developing web applications. [5] Flask is one of the python frame work which provide huge library support for developers and also helps in building efficient applications. Frame works also have capability to connect with data bases. We additionally utilized the python database connectivity for moving data into the database. [5] Python DB-API (database application program interface) is standard database interface, can be used to access relational databases.

\section{TEST ANALYSIS}

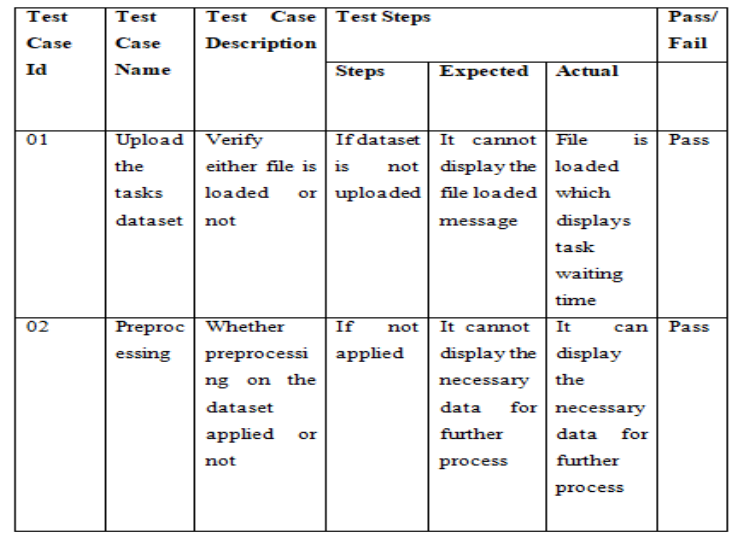

\subsection{EXPERIMENTAL RESULTS}

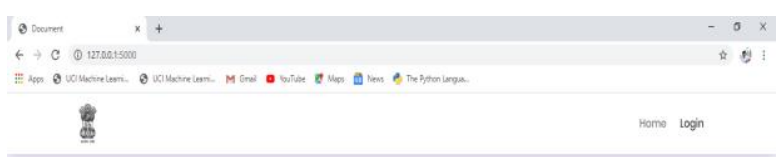

Licence Detection

Using QR Code

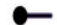

a $\rho$ 大

Fig. 2. HOME PAGE
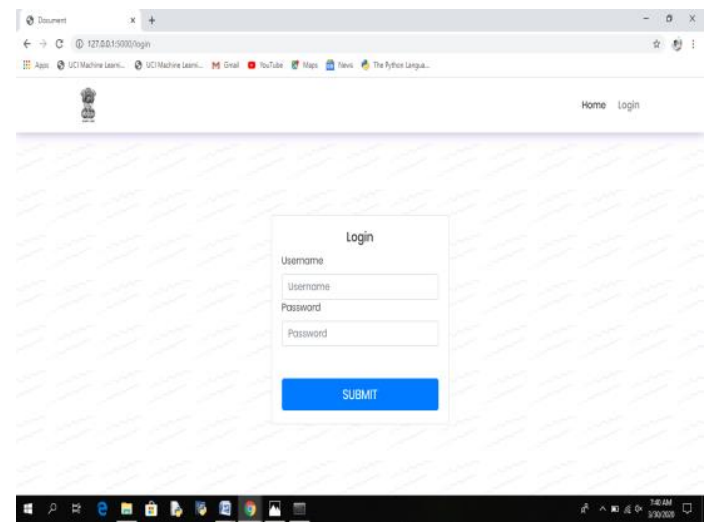

Fig. 3. LOGIN PAGE
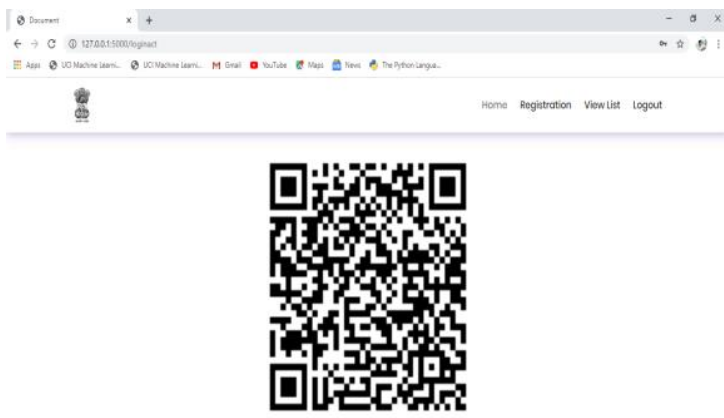

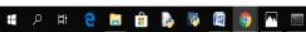

Fig. 4. QR CODE

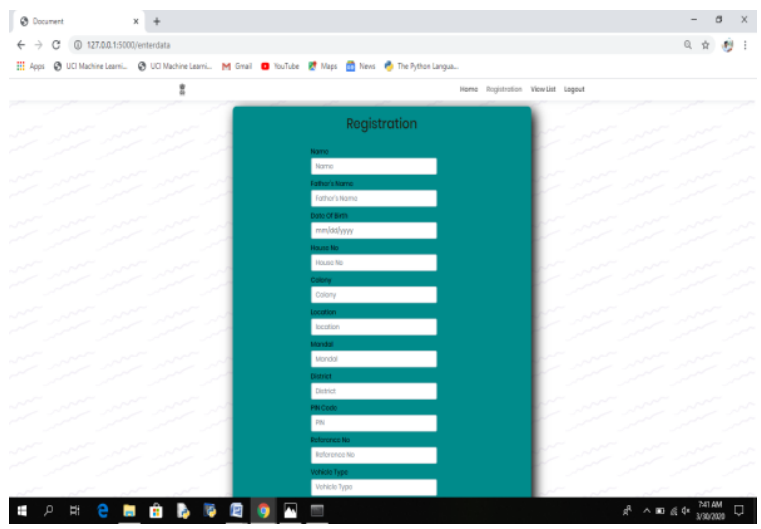

Fig. 5 .REGISTRATION PAGE

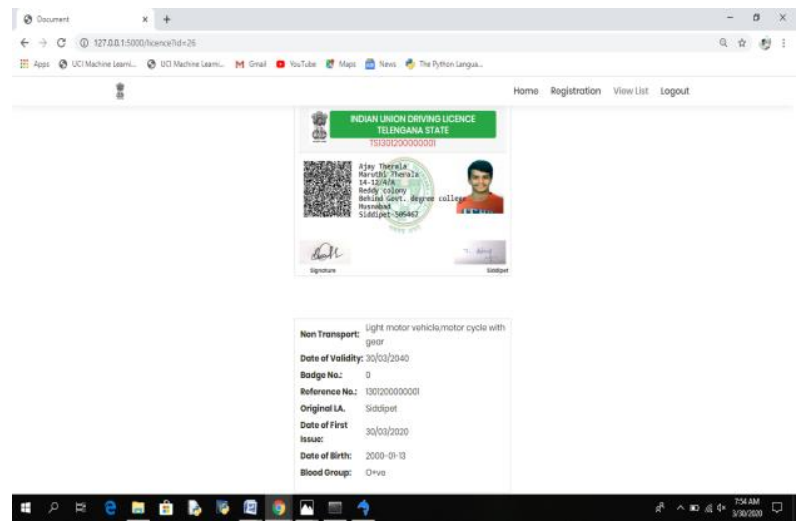

Fig. 6. DRIVING LICENSE WITH QR CODE 


$6: 04$
$\equiv \quad$ Scan
$\quad$ Text
$\quad 31$ Mar $20206: 04$ am
Name: Ajay Therala
Father's Name: Maruthi Therala
Date Of Birth: 2000-01-13
House No: $14-12 / 4 / A$
Colony: Reddy colony
Location: Behind Govt. degree college
Mandal: Husnabad
District: Siddipet
Pin: 505467
Date Of Issue: $30 / 03 / 2020$
Validity: $30 / 03 / 2040$

Fig. 7. INFORMATION RETRIEVED BY SCANNING QR CODE

\section{Conclusion and Future Intensification}

From this system we can conclude that scanning the QR code for obtaining details will be faster than reading from a smart chip. With this system we can also conclude that there is no need of special device like magnetic card readers which may cost around 1500, a smart phone is enough for scanning that $\mathrm{QR}$ code and the user can utilize the $\mathrm{QR}$ code as a default.

The requirements of user keeps on changing as the system is being used so it is impossible to develop the system such that it meets all the requirements of the user. Some of the future improvements that can be done to this system are:

1. We can update the system by adding new features such as vehicle registration, viewing challan history and we can design the system as desired with the help of technologies available.

2. Security of the system can be increased by SSO (single sign on) which is one of the emerging technology. It helps user to login once and have access to various applications.

3. We can integrate the system with Aadhar card.

\section{References}

1. Ihekweaba Chukwugoziem, Aru Okereke Eze, E. Chiaghana Chukwunonso, International Journal of scientific and engineering research ISJER, A Quick Response (QR) code generator with mobile scan application for mobile network recharge options, 10, (2019).

2. S.R. Bharamagoudar, R.B. Geeta, S.G. Totad, Journal at International journal of advanced research in computer and Communication engineering " $\mathrm{Web}$ based student information management system" $\mathbf{2}$ (2013).

3. Md. Sanaul Haque, Richard Dybowski, at First International Conference on systems Informatics, Modeling and Simulation "Advanced $Q R$ Code based Identity card: A new era for generating student ID card in developing countries" (2014).
4. Suresh Kumar Tummala, Dhasharatha G, E3S Web of Conferences 87, 01030 (2019)

5. Mr. Ankush Kudale, Dr. Binod Kumar, Journal at International Journal of Computer Application "Protected Authentication by Login Credential and OTP for Cloud Based Application", 5(2015).

6. Kalyani Adawadkar, at International Journal of Advance Engineering and Research Development "Pythonprogramming-Applications and Future", (2017).

7. Komal Chorghade, Piyush Dahiwele, Saurabh Deshmukh, Prof. Prajakta Pise at International Research Journal of Engineering and Technology. "RTO Automation Using QR Code", 5, (2018).

8. Rajagiri A, MN Sandhya, Nawaz S, Suresh Kumar T, E3S Web of Conferences 8701004 (2019) 